Methods: cohort retrospective study, the data being gathered from RRBR, which includes all the patients treated with biologics and targeted synthetic DMARDs in the country. Inclusion criteria: at least one treatment course of JAK inhibitors, until end of 2019. The collected data: demographic and disease characteristics, efficacy parameters (DAS28) and safety data (exposure to JAK inhibitors in person-years (PY) and reported adverse events (AE).

Results: the RA cohort treated with JAK inhibitors included 416 patients $(7.6 \%$ of all RA patients registered in RRBR) exposed to baricitinib (306 pts) or tofacitinib (110 pts) for 66255 PY. The mean age was 57.91 years, 365 (88\%) women, 41 (10\%) smokers, mean RA duration 11.32 years, 316 (76\%) RF positive, 254 (61\%) ACPA positive, 356 (85.5\%) patients associate a synthetic DMARD, 76 $(18 \%)$ use steroids $(66 \%<7.5 \mathrm{mg}$ prednisone/day); $268(65 \%)$ patients have cardiovascular comorbidities, 84 pts $(20 \%)$ have modified lipid profile, 89 patients $(21.4 \%)$ have latent TB, $86(20.7 \%)$ have resolved HBV infection state. JAK inhibitors were the first treatment option for 178 patients $(43 \%)$, all other patients have been exposed previously to at least one TNF-inhibitor or a biologic with another mode of action, being insufficient responders, as follows: 96 patients - to 1 biologic, 80 patients - to 2 biologics, 30 patients - to 3 biologics, 23 patients - to 4 biologics, 8 patients - to 5 biologics and 1 patient - to 7 molecules before the JAK inhibitors start. Of all patients exposed to JAK inhibitors, 252 (60.5\%) patients have continued the therapy since the start summarising $61481 \mathrm{PY}$ of exposure. The efficacy parameters reported to this category revealed a mean DAS28 score of 3.08 , significantly lower compared to 6 months before (4.77). Regardless the number of biologic agents used before starting a JAK inhibitor, there is no significant difference in DAS28 score when comparing it with DAS28 efficacy of the first treatment option scenario (3.10 vs 2.94, p>0.05). Steroid use, the presence of RF or disease duration have no influence on the efficacy DAS28. On contrary, the ACPA positivity subgroup has a significantly lower DAS28 score, compared to ACPA negativity ( 3.18 vs $3.82, p<0.05$ ); smoker status has a significantly higher DAS28 compared to non-smokers (3.58 vs $2.94, \mathrm{p}<0.05)$. A total number of $46 \mathrm{AEs}$ were reported for a total exposure of 66255PY. Infections were the most frequently reported $A E$ (0.04/100PY, with 27 events); 6 cases of herpes zoster infection (0.009/100PY, all mild); 3 MACE (0.004/100PY). There were 3 severe adverse events (0.004/100PY) (1 hepatitis non-viral, 2 MACE) with one fatal (acute myocardial infarction).

Conclusion: JAK inhibitors represent a safe and efficacious treatment option for patients with active RA.

Disclosure of Interests: Catalin Codreanu Consultant of: Speaker and consulting fees from AbbVie, Accord Healthcare, Alfasigma, Egis, Eli Lilly, Ewopharma, Genesis, Mylan, Novartis, Pfizer, Roche, Sandoz, UCB, Speakers bureau: Speaker and consulting fees from AbbVie, Accord Healthcare, Alfasigma, Egis, Eli Lilly, Ewopharma, Genesis, Mylan, Novartis, Pfizer, Roche, Sandoz, UCB, Corina Mogosan Consultant of: Speaker and consulting fees from AbbVie, Novartis, Pfizer, Roche, Sandoz, Speakers bureau: Speaker and consulting fees from AbbVie, Novartis, Pfizer, Roche, Sandoz, Denisa Predeteanu Consultant of: Speaker fee for: Pfizer, Abbvie, Roche, MSD, Speakers bureau: Speaker fee for: Pfizer, Abbvie, Roche, MSD, Simona Rednic: None declared, Magda Parvu Consultant of: Speaker fee and consultant: Pfizer, Novartis, Roche, Abbvie, UCB, Eli-Lilly, Speakers bureau: Speaker fee and consultant: Pfizer, Novartis, Roche, Abbvie, UCB, Eli-Lilly, Elena Rezus: None declared, Ruxandra lonescu Consultant of: Consulting fees from Abbvie, Eli-Lilly, Novartis, Pfizer, Roche, Sandoz, Speakers bureau: Consulting and speaker fees from Abbvie, Eli-Lilly, Novartis, Pfizer, Roche, Sandoz

DOI: 10.1136/annrheumdis-2020-eular.4563

\section{FRI0120 ORAL GLUCOCORTICOID USE IS ASSOCIATED WITH HYPERTENSION IN PATIENTS WITH RHEUMATOID ARTHRITIS}

R. E. Costello ${ }^{1}$, B. Birlie Yimer ${ }^{1}$, M. Jani ${ }^{1}$, W. Dixon ${ }^{1} .{ }^{1}$ The University of Manchester, Centre for Epidemiology Versus Arthritis, Manchester, United Kingdom

Background: Oral glucocorticoids (GC) are frequently prescribed to patients with rheumatoid arthritis (RA), however GC use is associated with a number of potential side effects. Hypertension is cited as a possible side effect, but few studies have specifically investigated GC-associated hypertension in patients with RA with conflicting results.

Objectives: The aim of this study was to determine whether GCs were associated with an increased risk of incident hypertension in a cohort of patients with RA.

Methods: A retrospective cohort of patients with incident RA and no hypertension at RA diagnosis were identified from UK primary care electronic health records (Clinical Practice Research Datalink). GC prescriptions were used to determine time-varying GC use and dose, categorised as: no use, $>0-4.9 \mathrm{mg} / \mathrm{day}, 5-7.4 \mathrm{mg} / \mathrm{day}, 7.5-14.9 \mathrm{mg} / \mathrm{day}, \geq 15 \mathrm{mg} /$ day. A 3-month risk attribution model was used where patients continued to remain at risk for 3 months after the end of prescriptions. Hypertension was identified if a patient had either: 1) 2 consecutive systolic blood pressure (BP) measurements $>140 \mathrm{mmHg}$ within a year, 2) 2 consecutive diastolic BP measurements
$>90 \mathrm{mmHg}$ within a year or 3) antihypertensive prescriptions on at least two occasions and a Read code for hypertension. Unadjusted and adjusted Cox proportional hazards $(\mathrm{PH})$ regression models were fitted to determine if there was an association between GC use and hypertension. Models were adjusted for baseline age, gender, baseline body mass index, baseline ever smoking, time-varying synthetic disease-modifying anti-rheumatic drug use time-varying non-steroidal anti-inflammatory drug use and baseline Charlson comorbidity index.

Results: There were 17,760 patients with incident RA and no hypertension. The cohort had a mean age of $56.3 \pm 12.7$ years and were predominantly female (68\%). 7,421 (42\%) were prescribed GCs during follow-up. There were 6,243 cases of incident hypertension over 97547 person years (pyrs) of follow-up, giving an incident rate of 64.1 per 1000 pyrs. Of those 1321 cases were in those exposed to GCs and 4922 were in those unexposed, giving incident rates of 87.6 per 1000 pyrs and 59.7 per 1000 pyrs, respectively. The adjusted Cox PH model indicated that recent GC use was associated with a $17 \%$ increased hazard of hypertension (hazard ratio: $1.17(95 \% \mathrm{Cl} 1.10$ to 1.24$)$ ). When categorised by dose, the adjusted model indicated only doses above $7.5 \mathrm{mg}$ were significantly associated with hypertension (Table 1).

Table 1. Unadjusted and adjusted Cox proportional hazards regression model results

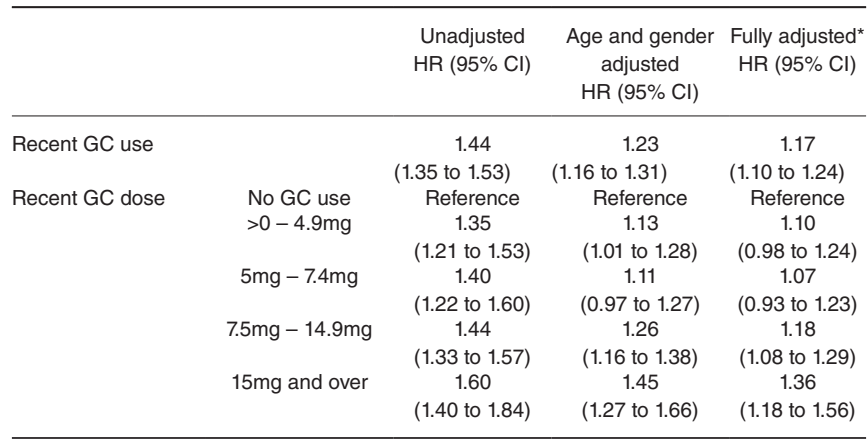

* Adjusted for: Baseline age, gender, baseline body mass index, baseline ever smoking, synthetic disease-modifying anti-rheumatic drug use (time-varying), non-steroidal anti-inflamma tory drug use (time-varying) and baseline Charlson comorbidity index.

Conclusion: In this large cohort of patients with RA and without hypertension, recent GC use was associated with incident hypertension. In particular doses $\geq 7.5 \mathrm{mg}$ were associated with hypertension while the association with lower doses was inconclusive. Clinicians need to consider cardiovascular risk when prescribing GCs and ensure BP is regularly monitored.

Disclosure of Interests: Ruth E Costello: None declared, Belay Birlie Yimer: None declared, Meghna Jani Speakers bureau: Grifols, William Dixon Consultant of: Bayer and Google

DOI: 10.1136/annrheumdis-2020-eular.1000

\section{FRI0121 STEROID-SPARING EFFECT OF JAK INHIBITORS IN RHEUMATOID ARTHRITIS PATIENTS FOLLOWED UP IN A REAL LIFE SETTING}

I. Duca ${ }^{1}$, F. R. Spinelli ${ }^{1}$, F. Ceccarelli ${ }^{1}$, C. Garufi ${ }^{1}$, S. Mancuso ${ }^{1}$, C. Alessandri ${ }^{1}$, R. Scrivo ${ }^{1}$, R. Priori ${ }^{1}$, V. Riccieri ${ }^{1}$, M. DI Franco ${ }^{1}$, F. Conti $^{1}{ }^{1}$ Sapienza Università di Roma, Rheumatology Unit, Rome, Italy

Background: Glucocorticoids (GCs) are a milestone of Rheumatoid Arthritis (RA) treatment; EULAR recommendations on the management of medium to high dose glucocorticoids remind to evaluate comorbidities and risk factors for adverse events when planning GCs treatment. Tofacitinib and Baricitinib are Janus kinases inhibitors (JAKi) registered for RA treatment. About $60 \%$ of patients enrolled in randomized clinical trials with JAKi were co-treated with GCs: however, little is known about tapering and percentage of withdrawal both in clinical trials and real life.

Objectives: To evaluate the steroid-sparing effect of JAKi in patients with RA. Methods: We prospectively enrolled consecutive adult patients with RA starting JAKi. At baseline and after 4, 12 and 24 weeks we calculated C-Reactive Protein based Disease Activity score 28 (DAS28 ${ }_{\mathrm{CRP}}$ ). Daily dose of GCs was recorded at each visit as prednisone (PDN)-equivalent dose. Data are expressed as median (IQR). Continuous variables were compared by Mann Whitney test while dichotomous ones by Chi-square test. $\mathrm{P}$ values $<0.05$ were considered statistically significant.

Results: Between January 2018 and January 2020, 108 patients started JAKi: 67 patients Baricitinib, 41 patients Tofacitinib. The analysis was restricted to 64 RA patients (50 female, 14 male) who had at least 6 months of follow-up. Table 1 shows the demographic, clinical and clinimetric characteristics of the cohort. 
Patients treated with baricitinib and tofacitinib were comparable for age, disease duration, PDN dose and previous number of csDMARDS and bDMARDS; 30 patients $(47.6 \%)$ were treated with JAKi in monotherapy. At baseline, the median daily PDN dose was 5 (7.25) $\mathrm{mg}$; after 4, 12 and 24 weeks the median daily dose significant decreased to 5 (6.25) $\mathrm{mg}, 2.5$ (5) $\mathrm{mg}$ and 0 (5) $\mathrm{mg}$, respectively $(p<0.0001)$. The percentage of patients treated with GC decreased from $81.5 \%$ to $63.5 \%$ at week 4 , and to $48.4 \%$ at week 12 and 24 . After 4,12 and 24 weeks we detected a significant reduction of DAS28 ( $<0.00001$ compared to baseline). A similar percentage of patients who withdrew PDN compared to those who were still on PDN achieved remission after 12 and 24 months. Similarly, the reduction in DAS28 was comparable between the two groups at week 4 [4.8 (4.2) in those who withdrew vs 4.1 (1) in those who did not] at week 12 [4.8(1.6) for both] and at week 24 [3.7 (1.4) in those who withdrew vs $2.3(0.7)$ in those who did not].

Table 1. Demographic, clinic and clinimetric characteristics of the 64 patients

\begin{tabular}{llll}
\hline & Baricitinib=41 & Tofacitinib=23 & P value \\
\hline Female:male & $33: 8$ & $17: 6$ & $\mathrm{P}=\mathrm{ns}$ \\
Age, median (IQR), years & $58(15)$ & $66(14.5)$ & $\mathrm{P}=\mathrm{ns}$ \\
Disease duration, median (IQR), months & $144(144)$ & $150(120)$ & $\mathrm{P}=\mathrm{ns}$ \\
$\mathrm{N}^{\circ}$ of previous csDMARDS & $3(3)$ & $3(1)$ & $\mathrm{P}=\mathrm{ns}$ \\
$\mathrm{N}^{\circ}$ of previous bDMARDs & $2(3)$ & $1(3)$ & $\mathrm{P}=\mathrm{ns}$ \\
$\mathrm{DAS28}$ cRP at baseline & $4.7(1.6)$ & $4.8(2)$ & $\mathrm{P}=\mathrm{ns}$ \\
$\mathrm{PDN}$ dose at baseline, median (IQR), mg & $5(7.5)$ & $5(5)$ & $\mathrm{P}=\mathrm{ns}$ \\
$\mathrm{PDN}$ dose at 4 weeks, median (IQR), mg & $5(7.5)$ & $5(5)$ & $\mathrm{P}=\mathrm{ns}$ \\
$\mathrm{PDN}$ dose at 12 weeks, median (IQR), mg & $2(5)$ & $2.5(4.7)$ & $\mathrm{P}=\mathrm{ns}$ \\
$\mathrm{PDN}$ dose at 24 weeks, median (IQR), mg & $0(5)$ & $2.5(0)$ & $\mathrm{P}=\mathrm{ns}$ \\
\hline
\end{tabular}

IQR: interquartile range; DAS28 ${ }_{C R P}$ : Disease Activity Score 28 using C-Reactive Protein, csDMARDS: conventional synthetic Disease Modyfing anti-rheumatics drugs, bDMARDS: biotheconological Disease Modifying anti-rheumatics drugs PDN= prednisone

Conclusion: The rapid reduction of disease activity determined by JAK inhibitors allows a fast tapering of PDN, as suggested by the last EULAR recommendations for the management of RA.

Disclosure of Interests: Ilaria Duca: None declared, Francesca Romana Spinelli Grant/research support from: Pfizer, Speakers bureau: Lilly, BMS, Celgene, Fulvia Ceccarelli: None declared, Cristina Garufi: None declared, Silvia Mancuso: None declared, cristiano alessandri Grant/research support from: Pfizer, Rossana Scrivo: None declared, Roberta Priori: None declared, Valeria Riccieri: None declared, Manuela Di Franco: None declared, fabrizio conti Speakers bureau: BMS, Lilly, Abbvie, Pfizer, Sanofi DOI: 10.1136/annrheumdis-2020-eular.5998

\begin{tabular}{|l|l}
\hline FRI0122 & EFFICACY AND PATIENT-REPORTED OUTCOME \\
MEASURES FROM A TWO-PART MULTICENTER, \\
PLACEBO-CONTROLLED, RANDOMIZED \\
WITHDRAWAL TRIAL OF REPOSITORY \\
CORTICOTROPIN INJECTION FOR PERSISTENTLY \\
ACTIVE RHEUMATOID ARTHRITIS
\end{tabular}

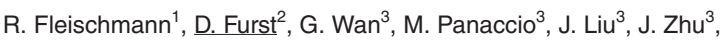
R. Brasington ${ }^{4} .{ }^{1}$ University of Texas Southwestern Medical Center, Metroplex Clinical Research Center, Dallas, United States of America; ${ }^{2}$ David Geffen School of Medicine, Los Angeles, United States of America; ${ }^{3}$ Mallinckrodt Pharmaceuticals, Bedminster, United States of America; ${ }^{4}$ Washington University School of Medicine, St Louis, United States of America

Background: Repository corticotropin injection $(\mathrm{RCl})$ is a naturally sourced complex mixture of adrenocorticotropic hormone analogs and other pituitary peptides approved for short-term adjunctive treatment of rheumatoid arthritis (RA).

Objectives: This two-part, international, multicenter, placebo (PBO)-controlled study assessed the efficacy of $\mathrm{RCl}$ in persistently active RA patients (pts) using clinical and patient-reported outcome measures (PROMs) (ClinicalTrials.gov NCT02919761).

Methods: Adults $\geq 18$ years with persistently active RA (DAS28-ESR >3.2) despite disease-modifying anti-rheumatic drug and glucocorticoid use received open-label $\mathrm{RCI}(80 \mathrm{U})$ subcutaneously $2 x /$ week (BIW) for 12 weeks (Part 1). Pts with DAS28-ESR $<3.2$ at Week (W) 12 entered the double-blind maintenance phase (Part 2) and were randomized to $80 \mathrm{U} \mathrm{RCI}$ or PBO BIW through W24. Efficacy endpoints included the proportion of pts who achieved DAS28-ESR $<3.2$ at W12 (primary) and maintained it through W24 (secondary). Mean changes from baseline (BL) were assessed for select PROMs (exploratory): Patient Global Assessment of Pain (PGAP); Patient Global Assessment of Disease Activity (PGADA); Health Assessment Questionnaire Disability Index (HAQ-DI); Functional Assessment of Chronic Illness Therapy - Fatigue (FACIT-F) scale; and Work Productivity and Activity Impairment (WPAI) questionnaire. Analyses used the modified intent-to-treat population (mITT-P; pts who received $\geq 1$ dose of study drug and contributed any efficacy data).
Results: In the mITT-P (N=259), 62.9\% ( $p<0.0001)$ achieved DAS28-ESR <3.2 at W12 (mean BL DAS28-ESR=6.3). In Part $2(\mathrm{RCl}, \mathrm{n}=77$; $\mathrm{PBO}, \mathrm{n}=76)$, more $\mathrm{RCl}$-treated pts maintained DAS28-ESR $<3.2$ at W24 $(62.3 \%, p=0.035)$ vs. PBO (43.4\%). Clinically significant improvements in PROMs from BL were observed through W12 and sustained to W24 (Table 1), with mean changes exceeding the reported minimal clinically important difference thresholds (MCIDs) for each. Conclusion: $\mathrm{RCl}$ for persistently active $\mathrm{RA}$ resulted in clinically significant improvements in efficacy endpoints and PROMs for up to 6 months in pts who continued and discontinued $\mathrm{RCl}$ after 3 months of initial therapy.

References:

Table 1. PROMs From the 12-week Double-blind Withdrawal Phase, mITT-P

\begin{tabular}{|c|c|c|c|c|c|c|c|c|c|c|}
\hline \multirow{3}{*}{$\begin{array}{c}\text { PROM } \\
\text { (Score range) } \\
\text { [MCOD] }\end{array}$} & \multirow{2}{*}{\multicolumn{2}{|c|}{$\begin{array}{l}\text { Baseline, } \\
\text { Mean (SD) }\end{array}$}} & \multicolumn{8}{|c|}{ Mean Change From Baseline (SD) } \\
\hline & & & \multicolumn{2}{|c|}{ Week 12} & \multicolumn{2}{|c|}{ Week 16} & \multicolumn{2}{|c|}{ Week 20} & \multicolumn{2}{|c|}{ Week 24} \\
\hline & RO & PBO & RCI & PBO & ROI & PBO & RCI & PBO & RCI & PBO \\
\hline \multirow{2}{*}{ PGAP (0-100) [10] } & 65.7 & 62.8 & -46.8 & -45.8 & -43.6 & -41.2 & -45.9 & -42.8 & -43.8 & -40.7 \\
\hline & (18.7) & (21.0) & (23.4) & (23.2) & (26.1) & (25.7) & (23.7) & (24.7) & (23.9) & (25.2) \\
\hline \multirow{2}{*}{ PGADA (0-100) [10] } & 68.0 & 61.4 & -48.1 & -41.9 & -44.5 & -39.5 & $-48.5^{*}$ & -39.9 & -45.9 & -39.3 \\
\hline & (16.6) & (20.0) & (20.9) & (24.5) & (25.3) & (26.5) & (21.5) & (27.7) & (24.6) & (28.2) \\
\hline \multirow{2}{*}{ FACIT-F (0-52) [4] } & 22.7 & 22.6 & -10.1 & -10.2 & -8.7 & -8.6 & -10.1 & -10.5 & -9.4 & -10.5 \\
\hline & (7.7) & (9.0) & (8.1) & (8.9) & (8.2) & (9.1) & (7.8) & (9.7) & (7.9) & (9.2) \\
\hline \multicolumn{11}{|c|}{ WPAl (\% due to RA) [N/A] } \\
\hline \multirow{2}{*}{ Work time missed } & 19.9 & 31.9 & -13.6 & -20.7 & -7.44 & -15.7 & -5.7 & -14.2 & -13.8 & -9.2 \\
\hline & (20.8) & (33.5) & (25.4) & (31.8) & (35.3) & (28.7) & (26.5) & (34.6) & (24.9) & $(32.0)$ \\
\hline \multirow{2}{*}{$\begin{array}{l}\text { Impairment while } \\
\text { working }\end{array}$} & 46.8 & 55.3 & -34.7 & -33.1 & -31.3 & -31.7 & -27.2 & -47.3 & -30.0 & -40.0 \\
\hline & (25.8) & (30.7) & (25.5) & (24.3) & (25.3) & (32.7) & (25.2) & (28.7) & (25.8) & (28.3) \\
\hline \multirow{2}{*}{$\begin{array}{l}\text { Overall work } \\
\text { impairment }\end{array}$} & 54.7 & 61.9 & -36.9 & -30.4 & -33.4 & -35.1 & -23.6 & -43.8 & -32.7 & -32.4 \\
\hline & (28.9) & $(33.4)$ & $(33.4)$ & (26.9) & (31.5) & (40.2) & (26.5) & (34.3) & (30.1) & (28.8) \\
\hline \multirow{2}{*}{$\begin{array}{l}\text { Activity } \\
\text { impairment }\end{array}$} & \begin{tabular}{|c|}
64.9 \\
\end{tabular} & 61.1 & -39.9 & -37.2 & -34.5 & -30.0 & -38.3 & -37.7 & -36.0 & -37.9 \\
\hline & (22.8) & (24.1) & (24.3) & (28.6) & (25.8) & (30.0) & (23.8) & (24.9) & (24.9) & (27.1) \\
\hline \multirow{2}{*}{ HAQ-DI (0-3) [0.22] } & 1.7 & 1.7 & -1.0 & -1.0 & -0.9 & -0.9 & -1.0 & -1.0 & -0.9 & -1.0 \\
\hline & $(0.5)$ & (0.6) & $(0.6)$ & $(0.6)$ & $(0.5)$ & (0.7) & $(0.6)$ & (0.6) & $(0.6)$ & (0.6) \\
\hline
\end{tabular}

Acknowledgments: Editorial support was provided by MedLogix Communications, LLC, Itasca, Illinois, under the direction of authors and funded by Mallinckrodt Pharmaceuticals.

Disclosure of Interests: Roy Fleischmann Grant/research support from: AbbVie, Akros, Amgen, AstraZeneca, Bristol-Myers Squibb, Boehringer, IngelhCentrexion, Eli Lilly, EMD Serono, Genentech, Gilead, Janssen, Merck, Nektar, Novartis, Pfizer, Regeneron Pharmaceuticals, Inc., Roche, Samsung, Sandoz, Sanofi Genzyme, Selecta, Taiho, UCB, Consultant of: AbbVie, ACEA, Amgen, Bristol-Myers Squibb, Eli Lilly, Gilead, GlaxoSmithKline, Novartis, Pfizer, Sanofi Genzyme, UCB, Daniel Furst Grant/research support from: AbbVie, Actelion, Amgen, BMS, Corbus Pharmaceuticals, the National Institutes of Health, Novartis, Pfizer, and Roche/Genentech, Consultant of: AbbVie, Actelion, Amgen, BMS, Cytori Therapeutics, Corbus Pharmaceuticals, the National Institutes of Health, Novartis, Pfizer, and Roche/Genentech, Speakers bureau: CMC Connect (McCann Health Company), George Wan Employee of: Mallinckrodt Pharmaceuticals, Mary Panaccio Employee of: Mallinckrodt Pharmaceuticals, Jingyu Liu Employee of: Mallinckrodt Pharmaceuticals, Julie Zhu Employee of: Mallinckrodt Pharmaceuticals, Richard Brasington Speakers bureau: Amgen, Mallinckrodt Pharmaceuticals, Novartis, and Pfizer

DOI: 10.1136/annrheumdis-2020-eular.1764

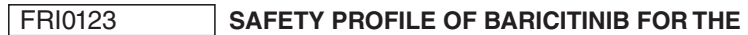 TREATMENT OF RHEUMATOID ARTHRITIS UP TO 8.4 YEARS: AN UPDATED INTEGRATED SAFETY ANALYSIS}

M. C. Genovese ${ }^{1}$, J. S. Smolen ${ }^{2}$, T. Takeuchi ${ }^{3}$, G. R. Burmester ${ }^{4}$, W. Deberdt ${ }^{5}$, D. Schlichting ${ }^{5}$, H. Song ${ }^{6}$, D. Mo ${ }^{5}$, C. Walls ${ }^{5}$, K. Winthrop ${ }^{7}$. ${ }^{1}$ Stanford University, Division of Immunology and Rheumatology, Palo Alto, $C A$, United States of America; ${ }^{2}$ Medical University of Vienna, Division of Rheumatology, Department of Medicine, Vienna, Austria; ${ }^{3}$ Keio University School of Medicine, Division of Rheumatology, Department of Internal Medicine, Tokyo, Japan; ${ }^{4}$ Charité-University Medicine Berlin, Free University and Humboldt University Berlin, Department of Rheumatology and Clinical Immunology, Berlin, Germany; ${ }^{5}$ Eli Lilly and Company, Indianapolis, IN, United States of America; ${ }^{6}$ Syneos Health, Morrisville, NC, United States of America; ${ }^{7}$ Oregon Health Sciences University, Portland, OR, United States of America

Background: Baricitinib (bari) is an oral selective inhibitor of Janus kinase (JAK) 1 and 2, approved for the treatment of moderately to severely active rheumatoid arthritis (RA) in adults. 